\title{
DIDELIO MEISTRIŠKUMO ŠAULĖS INDIVIDUALAUS METINIO RENGIMO OPTIMIZAVIMAS
}

\author{
Vaida Gulbinskienė, Antanas Skarbalius \\ Lietuvos kūno kultūros akademija, Kaunas, Lietuva
}

\begin{abstract}
Vaida Gulbinskienè. Socialinių mokslų (edukologijos) daktarè. Lietuvos kūno kultūros akademijos Sporto technologijų katedros asistentė, Sportininkų rengimo valdymo laboratorijos jaunesnioji mokslo darbuotoja. Moksliniu tyrimu kryptis - sportininkų rengimo valdymo modeliavimas.
\end{abstract}

\section{SANTRAUKA}

Tyrimo tikslas - optimizuoti individualuji šaulio rengimo modeli. Tyrimo objektas: šaulio rengimo ir parengtumo modelis. Priklausomas kintamasis - sportinis parengtumas (šaudymo rezultatas), nepriklausomas - modeliuota programa (rengimas su šoviniu, rengimas be šovinio). Taikytas vienos alternatyvos eksperimentas, modeliavimo ir testavimo metodai (techninis šaulio parengtumas vertintas Rika Home Trainer kompiuterine programa). Sasajos tarp kintamuju nustatytos SPSS 11.0 statistiniu paketu.

Eksperimento metu buvo tiriama didelio meistriškumo šaule V. M. (gimusi 1978 m., daugkartine Lietuvos šaudymo čempionè). Jai sudarytas ir 2001-2002 metais taikytas vyraujančio bendrojo rengimo 44 savaičiu trukmès rengimo modelis leido svarbiausose varžybose — Lietuvos šaudymo čempionate - pasiekti geriausiq sportiní rezultata.

Rengimo poveikis parengtumui vertintas pagal makrociklus ir mezociklus. Mezociklu metu nustatytas rengimo krūvio didinimo, mažinimo (suteikia informacijos apie adaptacija) ir atitinkama rezultatu kaitos ryšys. Taip pat nustatytas rezultatu didèjimo, mažèjimo (leido ęvertinti adaptacijos vélavima) ir atitinkamo rengimo laikotarpio ryšys. Išsamesnè analize leido nustatyti didelio meistriškumo šaulès $V$. M. individualiq optimaliq rengimo trukmę (21 savaičiu). Modelio seka atitinka superkompensacijos fenomena.

Nustatyta didelio meistriškumo šaulès V. M. individualaus optimalaus 21 savaitès trukmès rengimo modelio seka —aštuoniu

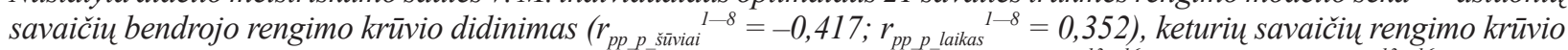

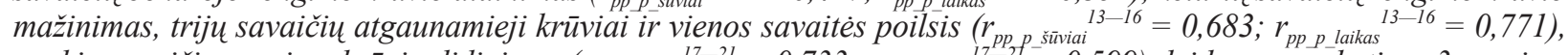

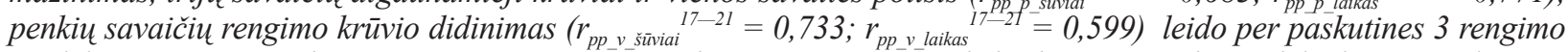
modelio savaites pasiekti geriausia sportinì meistriškuma ir patvirtino iškelta hipotezę. Toks modelis leistu rezultatams didèti dešimties savaičiu laikotarpiu.

Raktažoď̌iai: šaudymas, rengimas ir parengtumas, modeliavimas.

\section{IVADAS}

$\mathrm{S}$ portininku parengtumą daugiausia lemia rengimo (atletinio, techninio, taktinio, funkcinio pajègumo, psichinio, teorinio) rodikliu gausa. J. Perl su bendraautoriais (Mester, Perl, 2000; Perl, 2000, 2001, 2004) nustate orientacinius rengimo modelius, kurie galètų lemti dèsningą parengtumo modelių kaitą, tačiau kartu pabrèžè ir dažnai neprognozuojamą kintamą ryši tarp rengimo ir parengtumo modeliu. Remiantis sportininku rengimo ir parengtumo metamodelio teorija (Hull,
1943, 1952; Busso et al., 1990; Hohmann et al., 2000; Edelmann-Nusser et al., 2002; Perl, 2000, 2001) ir požiūriu, sportininko šaulio rengimas yra kompleksinè dinaminé sistema (Banister et al., 1975, 1999; Calvert et al., 1976), kurios ịvestimi laikomas rengimas (rengimas su šoviniu, rengimas be šovinio), o išeiga - parengtumas (šaudymo rezultatas). Todèl keliame hipotezę: didelio meistriškumo šaulio optimalus rengimo modelis lemia tik individualų parengtumą. 
Tyrimo objektas: šaulès rengimo ir parengtumo modelis.

Tyrimo tikslas - optimizuoti individualu šaulès rengimo modeli.

\section{METODAI}

Vienos alternatyvos metų trukmės eksperimentas. Atlikta studija (Bowman, 2000; Di Dona, 2000; Eagles, 2000; Nestruev, 2000; Snyder and Bright, 2000) taikant modeliavimo metodą leido sudaryti didelio meistriškumo šaulès V. M. (gimimo metai - 1978; rungtis — pistoletas; laimejjimai - 1997 metų Europos jaunimo pirmenybių bronzos laimėtoja, daugkartinè Lietuvos šaudymo čempionè) pratybu modeli ir siekta ivertinti rengimo krūvio rodiklių poveiki parengtumo kaitai. Buvo sudarytas vyraujančio bendrojo rengimo 44 savaičiu trukmés modelis.

Eksperimento metu, siekiant nustatyti didelio meistriškumo šaulès V. M. sportinio parengtumo kaitą, buvo analizuojami varžybų rezultatai, testuojama kompiuterine iranga su Rika Home Trainer (RHT) programa. Šia įranga buvo testuojama kartą per mènesi, prieš savaitę iki svarbiausių varžybų.

Protokole-dienoraštyje buvo registruojamas rengimo modelio (44 savaičiu) turinio (rengimo dienų, pratybų, varžybų, startų, poilsio dienų skai- čiaus per metus, metų pratybų ir varžybų šūvių skaičiaus (išskiriant Lietuvos ir tarptautines varžybas), šūvių skaičiaus pagal rengimo rūšis (technika, taktika, atletini, integraluji rengimą, pratybu trukmę), šaudymo trukmès varžybose (išskiriant Lietuvos ir tarptautines varžybas), rengimo be šovinio, atletinio, teorinio rengimo trukmès), šaudymo pistoletu PP-40, MK $30+30$ pratimu rezultatu kitimas.

Statistinė tyrimo duomenų analizė. Sąsajos tarp kintamuju nustatytos SPSS 11.0 statistiniu paketu pagal: Pirsono koreliacinę analizę (reikšmingumo lygmuo $\mathrm{p}<0,05$ ), kai duomenys atitinka normaluji skirstinį; Spirmeno koreliacinę analizę (reikšmingumo lygmuo $\mathrm{p}<0,05$ ), kai duomenys neatitinka normalaus skirstinio.

\section{REZULTATAI}

Vyraujančio bendrojo rengimo ir parengtumo rodikliai per 44 savaites kito i̇vairiai (1, 2 pav.), ryšys tarp makrociklo rengimo rodikliu (1 lent.) ir šaulès V. M. 2001 / 2002 metų PP-40 pratimo rezultatų nenustatytas.

Rengimo pradžioje ( $1-8$ savaitę), didinant šūvių skaičiuc, varžybų rezultatai blogèjo, o mažinant šūviu skaičiu (per 8-15 mikrociklą) ir rengimo laiką be šovinio - gerejjo. Kitu laiku (per 17-19 mikrociklą) didinant rengimo laiką be šovinio ir

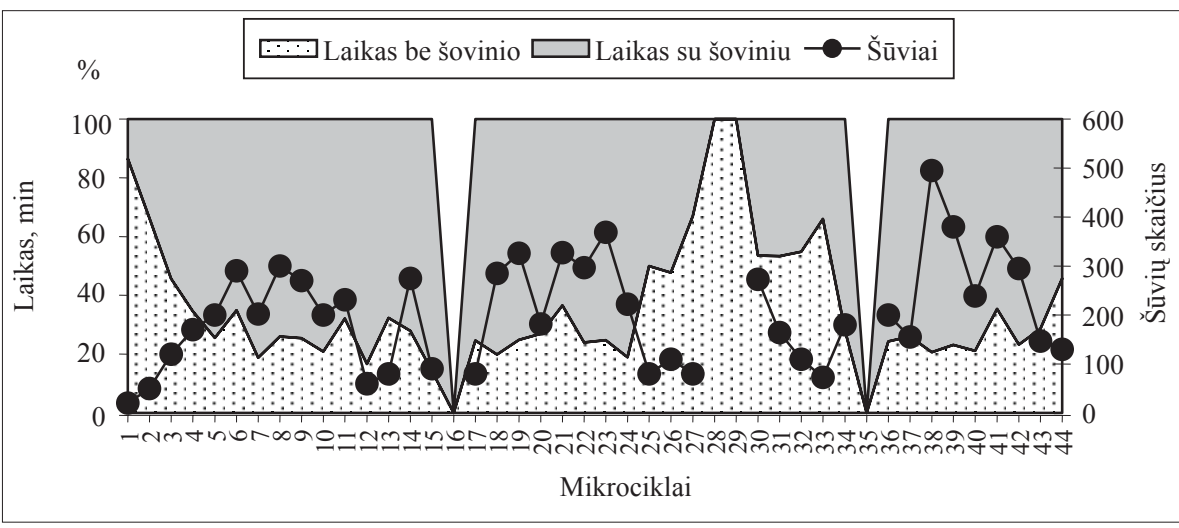

1 pav. Šaulès V. M. vyraujančio bendrojo rengimo 44 savaičių trukmès modelio rodiklių (šūvių skaičiaus, rengimo laiko su šoviniu ir be šovinio) kaita

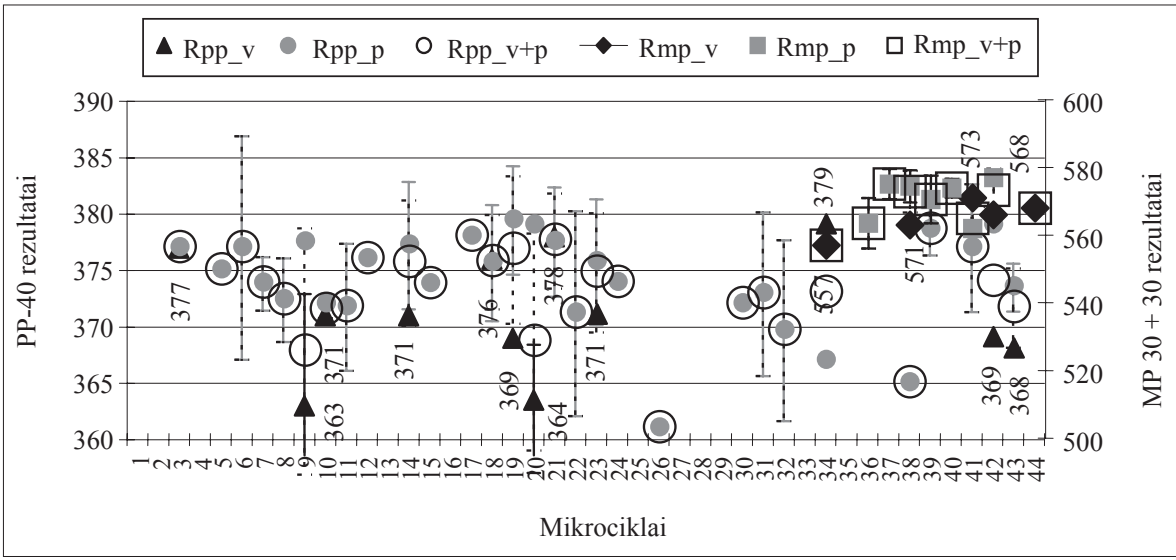

2 pav. Šaulès V. M. vyraujančio bendrojo rengimo 44 savaičiu trukmès modelio parengtumo (šaudymo rezultato) kaita $(\overline{\mathbf{X}} \pm \mathrm{SD})$

Pastaba. Rpp_v - PP-40 pratimo varžybu rezultatai; Rpp p — PP-40 pratimo pratybu rezultatai; $\mathrm{Rpp}_{-}$ $\mathrm{p}+\mathrm{v}-\mathrm{PP}-40$ pratimo pratybu ir varžybų rezultatai; Rmp_v - MP $30+30$ pratimo varžybu rezultatai; Rmp_p - MP $30+30$ pratimo pratybu rezultatai; Rmp $\mathrm{p}+\mathrm{v}-\mathrm{MP}$ $30+30$ pratimo pratybu ir varžybu rezultatai. 
1 lentelè. Didelio meistriškumo šaulès V. M. šūvių skaičiaus (šūvių), rengimo laiko be šovinio (laiko) ir rezultatų ryšys

\begin{tabular}{|c|c|c|c|c|c|c|c|c|c|c|c|}
\hline \multicolumn{2}{|l|}{$\mathrm{R}_{\mathrm{pp} \_\mathrm{v}}$} & \multicolumn{2}{|l|}{$\mathrm{R}_{\mathrm{pp} \_\mathrm{p}}$} & \multicolumn{2}{|l|}{$R_{p p \_p+v}$} & \multicolumn{2}{|l|}{$\mathrm{R}_{\mathrm{mp} \_\mathrm{v}}$} & \multicolumn{2}{|l|}{$R_{m p \_p}$} & \multicolumn{2}{|l|}{$R_{m p \_p+v}$} \\
\hline Šūviai & Laikas & Šūviai & Laikas & Šūviai & Laikas & Šūviai & Laikas & Šūviai & Laikas & Šūviai & Laikas \\
\hline$-0,051$ & 0,188 & 0,232 & $-0,024$ & 0,190 & 0,029 & 0,134 & 0,600 & 0,035 & $-0,288$ & 0,274 & $-0,268$ \\
\hline
\end{tabular}

Pastaba. Rpp_v — PP-40 pratimo varžybų rezultatai; Rpp_p — PP-40 pratimo pratybų rezultatai; Rpp_p + v — PP-40 pratimo pratybų ir varžybu rezultatai; Rmp_v — MP $30+30$ pratimo varžybų rezultatai; Rmp_p — MP $30+30$ pratimo pratybų rezultatai; Rmp_p + v — MP $30+30$ pratimo pratybų ir varžybų rezultatai.

šūviu skaičiu pratybų rezultatai gerèjo, varžybu rezultatas (19 mikrociklo metu) - tik 369 taškai. Kitą savaitę (per 20 mikrociklą) sumažinus rengimo laiką be šovinio ir šūviu skaičiu, tarptautiniu varžybu rezultatai pablogéjo penkiais $(363,5 \pm$ $4,95)$ taškais, pratybų rezultatas (379 taškai) - tik 0,45 taško.

Po Lietuvos šaudymo asmeninio čempionato (23 mikrociklo) vienos savaitės sumažintų rengimo krūvių (24 mikrociklo) buvo pradèta rengtis MP $30+30$ pratimui, todèl rengimo laikas be šovinio per penkis mikrociklus (25-29 mikrocikla) buvo didinamas nuo 90 iki $950 \mathrm{~min}$ per savaitę.

Po rengimo krūvio mažinimo 30-34 savaite tarptautinių šaudymo varžybų rezultatai (PP-40, MP $30+30)-379$ ir 557 taškai, tačiau krūvio apimties mažinimas iki pasaulio šaudymo čempionato neigiamai paveikẻ varžybų rezultatus (368 taškai) (43 mikrociklo metu), o MP 30+30 pratimo varžybų rezultatai gerèjo pasaulio šaudymo čempionate (568 taškai).

\section{REZULTATUQ APTARIMAS}

Rengimo modelio poveikio sportiniam parengtumui analizè atskleide teigiamą ir neigiamą ryši, t. y. dar kartą pagrindè J. Perl $(2000,2001,2004)$, J. Perl, P. Dauscher, M. Hawlitzky (2002) tyrimu išvadas apie kontroversiškumą arba prieštaravima, taip pat patvirtino ir dinaminès sistemos atstovu (Busso et al., 1997; Hohmann et al., 2000) sportininko adaptacijos prie rengimo krūvių ivairovès koncepcija. Remiantis T. Busso ir bendraautoriu (1994) tyrimų rezultatais, didelio meistriškumo šaulès rezultatų blogejimą būtų galima paaiškinti nuovargiu dèl rengimo pradžioje didinto šũviu skaičiaus, o rezultatu mažèimą - P. C. Zarkadas, J. B. Carter, E. W. Banister (1995) tyrimu išvadomis: netinkamai buvo taikytas rengimo programos turinys - per vèlai pradèta mažinti rengimo krūvio apimtis neigiamai paveikẻ sportinius rezultatus.

Mokslininku M. J. Gibala ir kt. (1994), E. W. Banister ir kt. (1999), Z. N. Kubukeli ir kt. (2002), I. Mujika ir kt. (2002) tyrimais nustatyta, kad sportinio parengtumo išlaikymą lemia rengimo krūvio mažinimas ir intensyvumo didinimas. Rengiant šaulę reikèjo mažinti šuvių skaičių ir (arba) rengimo laiką be šovinio, didinti varžybu šūvių skaičių.

Nors nereikšmingas ryšys tarp didelio meistriškumo šaulès V. M. makrociklo vyraujančio bendrojo rengimo ir parengtumo patvirtino sporto mokslininku (Mester et al., 2000; Perl, 2001) tyrimu išvadas, tačiau buvo ieškoma adaptacijos pagrindimo. Anot J. Perl (2000, 2004), labai svarbu ivertinti adaptacijos vèlavima, todèl jis siūlo nustatyti rezultatu kaitos nuo geriausio iki

\begin{abstract}
2 lentelè. Didelio meistriškumo šaulès V. M. PP-40 pratimo geriausių (blogiausių), blogiausių (geriausių) rezultatų laikotarpiụ ir parengtumo rodikliụ ryšys
\end{abstract}

Pastaba. PP_v - PP-40 pratimo varžybu rezultatai; PP_p - PP 40 pratimo pratybu rezultatai; P_p + v - PP-40 pratimo pratybu ir varžybu rezultatai. Gerẻjo - nurodytais mikrociklais šaudymo rezultatai gerèjo. Blogèjo - nurodytais mikrociklais šaudymo rezultatai blogejo.

\begin{tabular}{|c|c|c|c|c|c|c|c|c|c|c|c|}
\hline \multicolumn{4}{|c|}{ PP_v ir parengtumo ryšys } & \multicolumn{4}{|c|}{ PP_p ir parengtumo ryšys } & \multicolumn{4}{|c|}{ PP_p + v ir parengtumo ryšys } \\
\hline 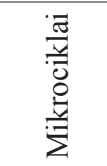 & 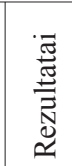 & 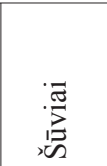 & 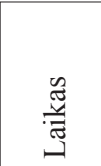 & 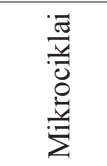 & 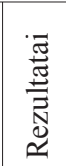 & 胥 & 恚 & 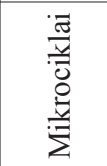 & 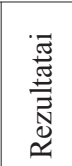 & 胥 & 莺 \\
\hline 3 & 377 & & & 3 & 377 & & & 3 & 377 & & \\
\hline $4-9$ & 363 & - & - & 4-11 & 372 & $-0,076$ & 0,278 & $4-11$ & 372 & $-0,375$ & 0,221 \\
\hline $10-18$ & 376 & 0,060 & $-0,346$ & $12-19$ & 379 & 0,212 & 0,097 & $12-17$ & 378 & $-0,435$ & $-0,450$ \\
\hline $19-20$ & 364 & 0,643 & 0,022 & $20-26$ & 361 & 0,626 & 0,207 & $18-26$ & 361 & 0,444 & 0,099 \\
\hline \multirow{2}{*}{$21-34$} & \multirow{2}{*}{379} & \multirow{2}{*}{0,180} & \multirow{2}{*}{0,405} & $27-31$ & 373 & 0,707 & 0,726 & $27-31$ & 373 & 0,707 & 0,726 \\
\hline & & & & $32-38$ & 365 & $-0,718$ & 0,680 & $32-38$ & 365 & $-0,828$ & $-0,084$ \\
\hline $35-43$ & 368 & $-0,225$ & $-0,108$ & $39-42$ & 379 & $-0,918$ & $-0,168$ & $39-43$ & 372 & $-0,263$ & 0,140 \\
\hline
\end{tabular}




\begin{tabular}{|c|c|c|c|c|c|c|c|c|}
\hline \multirow{2}{*}{ Data } & \multirow{2}{*}{ Rengimo kryptys } & \multirow{2}{*}{$\begin{array}{l}\text { Mikro- } \\
\text { ciklai }\end{array}$} & \multicolumn{2}{|c|}{$\begin{array}{l}\mathrm{PP}_{-} \mathrm{v} \text { ir pareng- } \\
\text { tumo ryšys }\end{array}$} & \multicolumn{2}{|c|}{$\begin{array}{l}\mathrm{PP} \_\mathrm{p} \text { ir pareng- } \\
\text { tumo ryšys }\end{array}$} & \multicolumn{2}{|c|}{$\begin{array}{l}\mathrm{PP} \_\mathrm{p}+\mathrm{v} \text { ir pa- } \\
\text { rengtumo ryšys }\end{array}$} \\
\hline & & & Šūviai & Laikas & Šūviai & Laikas & Šūviai & Laikas \\
\hline $\begin{array}{l}200109 \\
10-1104\end{array}$ & Bendrasis & $1-8$ & - & - & $-0,417$ & 0,352 & $-0,417$ & 0,352 \\
\hline $\begin{array}{l}200111 \\
05-1202\end{array}$ & Specifinis & $9-12$ & - & - & $-0,267$ & $-0,378$ & $-0,753$ & $-0,638$ \\
\hline $\begin{array}{l}200112 \\
03-23\end{array}$ & Atgaunamasis & $13-15$ & - & - & 0,683 & 0,771 & 0,252 & 0,375 \\
\hline $\begin{array}{lll}2001 & 12 & 24 \\
2002 & 0217\end{array}$ & Specifinis & $16-23$ & 0,580 & 0,583 & $-0,298$ & 0,014 & 0,057 & 0,220 \\
\hline $\begin{array}{l}200202 \\
18-03 \quad 17\end{array}$ & Integralusis & $24-27$ & - & - & 0,884 & $-0,035$ & 0,856 & $-0,092$ \\
\hline $\begin{array}{l}200203 \\
18-0414\end{array}$ & Bendrasis & $28-31$ & - & - & - & - & - & - \\
\hline $\begin{array}{l}200204 \\
15-0526\end{array}$ & \multirow{2}{*}{ Specifinis } & $32-38$ & - & - & $-0,162$ & 0,979 & 0,980 & $-0,170$ \\
\hline $\begin{array}{l}200205 \\
27-0712\end{array}$ & & $39-44$ & - & - & $-0,427$ & $-0,054$ & $-0,263$ & 0,140 \\
\hline
\end{tabular}

3 lentelè. Didelio meistriškumo šaulès V. M. PP-40 pratimo rezultatų ir parengtumo rodiklių ryšys

Pastaba. PP_v - PP-40 pratimo varžybu rezultatai; PP $\mathrm{p}-\mathrm{PP}-40$ pratimo pratybu rezultatai; PP $\mathrm{p}+\mathrm{v}-\mathrm{PP}-40$ pratimo pratybų ir varžybų rezultatai.

\begin{tabular}{|c|c|c|c|c|}
\hline \multicolumn{5}{|c|}{ Mezociklai } \\
\hline Ivadinis & Bazinis & \multicolumn{2}{|c|}{ Kontrolinis parengiamasis } & Varžybų \\
\hline \multicolumn{2}{|c|}{$\begin{array}{l}8 \text { savaičių bendrojo rengi- } \\
\text { mo modelis }\end{array}$} & \multicolumn{3}{|c|}{13 savaičių specifinio rengimo modelis } \\
\hline \multicolumn{2}{|c|}{$\begin{array}{l}8 \text { savaičiu rengimo krūvio } \\
\text { didinimas nuo } 35 \text { iki } 70 \% \\
\text { viso pratybų laiko per } \\
\text { savaitę }\end{array}$} & $\begin{array}{l}4 \text { savaičių } \\
\text { rengimo krūvio } \\
\text { mažinimas }\end{array}$ & $\begin{array}{l}3 \text { savaičiu atgaunamieji } \\
\text { rengimo krūviai ir } 1 \\
\text { savaitės poilsis }\end{array}$ & $\begin{array}{l}5 \text { savaičių rengimo } \\
\text { krūvio didinimas }\end{array}$ \\
\hline \multicolumn{2}{|c|}{$\begin{array}{l}\mathrm{r}_{\mathrm{pp \_} \_\_ \text {suviai }}{ }^{1-8}=-0,417 \\
\mathrm{r}_{\text {pp_p_laikas }}{ }^{1-8}=0,352\end{array}$} & & $\begin{array}{l}\mathrm{r}_{\text {pp____ǔviaia }}{ }^{13-16}=0,683 \\
\mathrm{r}_{\text {pp____laikas }}{ }^{13-16}=0,771\end{array}$ & $\begin{array}{l}\mathrm{r}_{\text {pp_v_zúviai }}{ }^{17-21}=0,733 \\
\mathrm{r}_{\text {pp_v_laikas }}{ }^{17-21}=0,599\end{array}$ \\
\hline
\end{tabular}

4 lentelè. Didelio meistriškumo šaulès individualaus optimalaus 21 savaitès trukmès rengimo modelis

blogiausio, nuo blogiausio iki geriausio ir rengimo programos tarpusavio ryši (2 lent.).

Sporto mokslininkai (Busso et al., 1990; Hartmann, Mester, 2000; Brannen, 2005) teigia, kad yra trumpalaikių rengimo ir parengtumo modelių ryšys. Todèl pagal A. Hohmann ir kt. (2001), J. Perl $(2001,2004)$ atliktų tyrimų metodiką didelio meistriškumo šaulès V. M. rengimas buvo optimizuojamas nustačius rengimo krūvio apimties pokyčius (nuo mažo krūvio link didelio ir nuo didelio link mažo) ir įvertinus sąsajas su atitinkamų laikotarpių sportiniu parengtumu — šaudymo rezultatu (3 lent.). Čia labai svarbi J. Perl (2004) išvada, kad mažos trukmès arba nedidelio krūvio rengimo modeliai apibūdinami kaip stabilūs ir, žinant kiekybinius jeigos parametrus bei esant palankiems pokyčiams sistemos viduje, būtų galima numatyti kiekybinius sportinio parengtumo rodiklius.

Išsamesnè analizè leido nustatyti didelio meistriškumo šaulès V. M. individualaus optimalaus rengimo trukmę (21 savaitès). Modelio seka atitinka superkompensacijos fenomeną (4 lent.).

Toks modelis leistų rezultatams gerèti dešimties savaičių laikotarpiu.

\section{IŠVADOS}

Nustatyta didelio meistriškumo šaulès V. M. individualaus optimalaus 21 savaitès trukmès rengimo modelio seka - aštuonių savaičių bendrojo rengimo krūvio apimties didinimas, keturių savaičių rengimo krūvio apimties mažinimas, trijų savaičiú atgaunamieji krūviai, vienos savaitès poilsis, penkių savaičių rengimo krūvio apimties didinimas - leido per paskutines 3 rengimo modelio savaites pasiekti geriausią sportinị meistriškumą ir patvirtino iškeltą hipotezę. 


\section{LITERATŪRA}

Banister, E. W., Calvert, T. W., MSavage, V., Bach, T. (1975). A systems model of training for athletic performance. Australian Journal of Sports Medicine, 7, 57-61.

Banister, E. W., Carter, J. B., Zarkadas, P. C. (1999). Training theory and taper: Validation in triathlon athletes. Journal of Applied Physiology, 79 (2), 182-191.

Bowman, J. (2000). Interview with Janine Bowman. Prieiga per interneta: http://www.pilkguns.com/intjb.htm

Brannen, A. (2005). Annual Planning. UKA Combined Events Conference, Loughborough.

Busso, T., Candau, R., Lacour, J. R. (1994). Fatigue and fitness modelled from the effects of training on performance. European Journal of Applied Physiology, 69 (1), $50-54$.

Busso, T., Denis, Ch., Bonnefoy, R., Geyssant, A. and Lacour, J. R. (1997). Modeling of adaptations to physical training by using a recursive least squares algorithm. Journal of Applied Physiology, 82, 1685-1693.

Busso, T., Hakkinen, K., Pakarinen, A. et al. (1990). A systems model of training responses and its relationship to hormonal responses in elite weight-lifters. European Journal of Applied Physiology, 61 (1-2), 48-54.

Calvert, T. W., Banister, E. W., Savage, M. V., Bach, T. M. (1976). A systems model of the effects of training on physical performance. IEEE Trans. Systems Man Cybernet, 6, 94-102.

Di Dona, R. (2000). Interview with Roberto Di Dona. Prieiga per interneta: http://www.pilkguns.com/intrdd.htm

Eagles, K. (2000). Interview with Kim Eagles. Prieiga per intenetą: http://www.pilkguns.com/intke.htm

Edelmann-Nusser, J., Hohmann, A., Henneberg, B. (2002). Modeling and Prediction of Competitive Performance in Swimming upon Neural Networks. European Journal of Sport Science, 2 (2), 1-10.

Gibala, M. J., MacDougall, J. D., Sale, D. G. (1994). The Effect of Tapering on Strength Performance in Trained Athletes. International Journal of Sport Medicine, 15, 492-497.

Hartmann, U., Mester, J. (2000). Training and overtraining markers in selected sport events. Medicine \& Sport in Science \& Exercise, 32, 209-215.

Hohmann, A., Edelmann-Nusser, J., Henneberg, B. (2000). A Nonlinear Approach to the Analysis \& Modeling of Training \& Adaptation in Swimming. In R. Sanders \& Y. Hong (Eds.), Application of Biomechanical Study in Swimming,
Proceedings of the XVIII International Symposium on Biomechanics in Sports (pp. 31-38). Hong Kong.

Hull, C. L. (1952). A behavior system: An introduction to behavior theory concerning the individual organism. New Haven: Yale University.

Hull, C. L. (1943). Principles of Behavior. New York: Appleton-Century-Crofts.

Kubukeli, Z. N., Noakes, T. D., Dennis, S. C. (2002). Training techniques to improve endurance exercise performances. Sports Medicine, 32 (8), 489-509.

Mester, J. \& Perl, J. (2000). Grenzen der Anpassung- und Leistungsfähigkeit aus systemischer Sicht- Zeitreihenanalyse und ein informatisches Metamodell zur Untersuchung physiologischer Adaptionsprozesse. Leistungssport, 30 (1), 43-51.

Mujika, I., Goya, A., Ruiz, E. et al. (2002). Physiological and performance responses to a 6-day taper in middle-distance runners: Influence of training frequency. Internationals Journal of Sports Medicine, 23, 367-373.

Nestruev, M. (2000). Interview with Michail Nestruev. Prieiga per internetą: http://pilkguns.com/intmn.htm

Perl, J. (2000). Antagonistic Adaptation Systems: An Example of How to Improve Understanding and Simulating Complex System Behaviour by Use of Meta-Models and On Line-Simulation: Conference Contribution for IMACS 2000, Lausanne.

Perl, J., Dauscher, P., Hawlitzky, M. (2002). On the LongTerm Behaviour of the Performance-Potential Metamodel PerPot. In the book of the abstract for the 7th Annual Congress of the European College of Sport Science. Prieiga per internetą: http://www.informatik.uni-mainz.de/dycon/ ECSS2002.LTPerPot.pdf

Perl, J. (2004). Modelling Dynamics Systems — basic aspects and applications to performance analysis. International Journal of Sport Science in Sport, 3 (2), 19-28.

Perl, J. (2001). PerPot: A metamodel for simulation of load performance interaction. Electronic Journal of Sport Science, 1 (2), 1-17.

Snyder, B., Bright, R. (2000). Interview with Beki Snyder and Rhonda Bright. Prieiga per internetą: http://www. pilkguns.com/intbsrb.htm

Zarkadas, P. C., Carter, J. B., Banister, E. W. (1995). Modelling the effect of taper on performance, maximal oxygen uptake, and the anaerobic threshold in endurance thriathletes. Advances in Experimental Medicine and Biology, 393, 179-186. 


\title{
OPTIMIZATION OF THE INDIVIDUAL SPORT PERFORMANCE DEVELOPMENT OF SHOOTERS
}

\author{
Vaida Gulbinskienė, Antanas Skarbalius \\ Lithuanian Academy of Physical Education, Kaunas, Lithuania
}

\begin{abstract}
The aim of the research was to optimize the individual training model of shooters. Research object: the model of training and sport performance of shooters. The dependent variable of this experiment was sport performance (sports result), while the independent variable was a modeled program (training with a shot and without a shot). One alternative experiment, modeling and testing (the shooter's technical fitness was tested by the computer equipment with Rika Home Trainer program) methods were applied. Interactions between the variables were determined on the SPSS 11.0 statistical package. The dominant training 44 week general model was applied for the shooter V. M. (born in 1978; multifold Lithuanian shooting champion), and in the period of 2001-2002. The best result was achieved at the most important competition - Lithuanian shooting championship.

Interrelation between the sport performance (shooting result) and the macro cycle training was computed. Training periodization with changing dynamic training volume / intensity (from small towards big and from big towards small) provided information about adaptation. The interrelation of the shifts from the best and the worst results and from the worst to the best together with the training program let us evaluate the adaptation delay. The detailed analysis allowed to determine the individual optimal training model duration -21 weeks. The sequence of the model corresponded to the overcompensation phenomenon.

The determined individual 21 week training and performance model sequence - increase of an eight week general training volume $\left(\mathrm{r}_{\mathrm{pp} \_ \text {__shots }}{ }^{1-8}=-0,417 ; \mathrm{r}_{\mathrm{pp} \_ \text {__time }}{ }^{1-8}=0,352\right)$, decrease of a four week training volume, 3 weeks of refreshing loads and 1 week of rest $\left(\mathrm{r}_{\mathrm{pp} \_ \text {_ s shots }}^{13-16}=0,683 ; \mathrm{r}_{\mathrm{pp} \_ \text {__time }}{ }^{13-16}=0,771\right)$, increase of a 5 week training volume $\left(\mathrm{r}_{\mathrm{pp} \_ \text {_ shots }}{ }^{17-21}=0,733 ; \mathrm{r}_{\mathrm{pp} \_ \text {_ time }}{ }_{17-21}=0,599\right)$ - allowed the shooter to reach the best sport performance during the last three training model weeks. Such findings confirmed the raised hypothesis.
\end{abstract}

Keywords: shooting, training and sport performance, modeling.

Gauta 2007 m. vasario 13 d.

Received on February 13, 2007

Priimta $2007 \mathrm{~m}$. birželio $13 \mathrm{~d}$

Accepted on June 13, 2007
Vaida Gulbinskienè

Lietuvos kūno kultūros akademija

(Lithuanian Academy of Physical Education)

Sporto g. 6, LT-44221 Kaunas

Lietuva (Lithuania)

Tel +37061215138

E-mail v.gulbinskiene@1kka.1t 